\title{
German research fights back
}

\section{Munich}

THE naming of the first "animal protection official" in West Germany has mobilized some of the country's top researchers in defence of the use of animals in research. Although protests from researchers have already led to limits on the power of the new official, the creation of the post reflects the growing political power of animal rights activists. Important changes in the way research with animals is regulated and monitored by the state may follow.

Researchers were so confident of their postion that they supported MinisterPresident Walter Wallmann (Christian Democrat) of the Land of Hesse when he created the new post. Researchers felt that their right to do experiments using animals was effectively protected by West German law.

Every experiment must be approved by a committee consisting of a two-thirds majority of 'experts' from the fields of medicine, biology and veterinary science.

But the man Wallmann nominated, the journalist and animal rights activist Ilya Weiss, was seen as the last person researchers wanted in the job. Researchers are now worried that the fashion of having an 'animal ombudsman' may spread to other Länder or to the federal government.

Weiss, who is 36 years old, is due to begin his duties on 1 January. He has been one of the most ardent advocates of the animal liberation movement in West Germany and publicly supported such actions as the 'freeing' of macaques from the research unit of INSERM in Lyons (see Nature 339, 407; 1989). Weiss was the head of a West German animal rights organization, and has conducted a 14-year crusade against the abuse of animals. He once locked himself in a huge cage in a central Frankfurt square for several days in order to dramatize the plight of animals used in research.

Weiss will have two full-time employees and an estimated budget of DM500,000 $(\$ 290,000)$. His official task will be to observe the application of the West German Animal Protection Law in Hesse and to suggest improvements in the interest of animals in both agriculture and research. He will act as an agent for Hesse in animal protection matters on both a national and a European level.

On 30 November, Wallmann met with representatives of the employees' committee at Hoechst AG, the pharmaceutical manufacturer, which is based in Hesse. On 7 December, he met more than a dozen senior researchers and doctors, some of whom came from other Länder to warn him of the possible consequences of Weiss's nomination.

Wallmann assured both groups that
Hesse would remain an attractive location for research and industry and that he did not intend to limit animal experimentation "as long as it is necessary". Furthermore, he assured researchers that Weiss would have to clear all of his public statements with the government.

Researchers were disappointed, however, that Wallmann did not forbid Weiss access to the documents that researchers must file in order to gain permission to carry out experiments with animals. They fear that Weiss will pass on the contents of the files to animal-rights activists who might attack individual researchers.

Although animal-rights activity receded after the Animal Protection Act was redrafted by parliament in 1985, the potential for activity is still present - the national animal rights organization 'Deutscher Tierschutzbund' has 600,000 members, about one per cent of the population of West Germany. Peter Gutjahr-Löser, who follows the issue for the Max Planck Society, foresees an upsurge of activity.

A spokeswoman for the granting agency Deutsche Forschungsgemeinschaft (DFG), said that DFG preferred to wait and see what else happens in Hesse before taking any public action. It is important, she said, to see if Weiss does his job properly before responding.

Researchers are especially worried that they would lose support if they are forced to fight in public for the cause of animals experimentation instead of just in private meetings with politicians. "If we had to go up against Weiss in a television debate, we would lose", said Wässle, because "we are amateurs and he is a trained professional." Weiss makes blanket statements condemning the use of animals, whereas researchers are trained to explain complicated issues in a qualified and cautious way, said Wässle. There is no doubt about which method comes across better.

Wässle rejected tactics such as sending leaflets to all the physicians in the country asking them to make their patients aware of the medical need for animal experiments. Although such tactics have been used by researchers in the United States, they would be seen as exploitation of the patients in West Germany, he said.

But not all the news is bad for researchers. The history of disagreements within the animal rights movement may reduce the threat to research. Some activists opposed the nomination of Weiss to the post in Hesse because they felt he was too radical.

Gutjahr-Löser admitted that Weiss's nominations "could have some positive effects" by raising the consciousness of researchers about animal rights. But researchers "do not need Weiss to make them think".

It would make more sense, he said, to hire more experts and veterinarians for the animal protection bureaucracy in order to speed up the application process, which has begun to fall far behind the timetable guaranteed by the law, and to increase vigilance against possible abuse of the animals.

\section{ANTARCTIC RESEARCH}

\section{New Indian base planned on Weddell Sea}

\section{New Delhi}

INDIA has despatched an expedition team on a chartered ship to the coast of the Weddell Sea in Antarctica with the eventual aim of establishing a new permanent base in that region. Known to be rich in mineral resources, it lies in an area where Britain, Chile and Argentina have overlapping territorial claims.

The 21-member expeditionary team, which left on 4 December, is led by Dr B.K. Raina of the Geological Survey of India. The team includes five scientists and 16 members of the Army, Navy, and Air Force. This is the ninth expedition to Antarctica since 1982, when the Department of Ocean Development (DOD) set up a station named Dakshin Gangotri at 70 degrees south and 12 degrees east. The station, located on shelf ice, began to drift and in $\mathbf{1 9 8 6}$ the Indian team set up a second camp about $80 \mathrm{~km}$ inland. A permanent base has now been established there.

The expedition to the Weddell Sea area is a sign that India's Antarctic activities will diversify. Vinod K. Gaur, the new Secretary of the Department of Ocean Development says the team will conduct geological studies, and that the department will eventually establish a permanent station there.

India is a consultative member of the Antarctic Treaty and has been a member of the Scientific Committee on Antarctic Research since 1984. So far, the Department of Ocean Development has spent about $\$ 30$ million on its eight expeditions.

The department intends to purchase a ship for future expeditions and has asked the government for about $\$ 60$ million for Antarctic research between now and 1995.

India does not recognize the territorial claims in Antarctica of any countries and says its present goals in Antarctica are purely scientific. But it has been stated officially that economic benefits for India can come from knowledge of the krill stock, and a fisheries vessel capable of operating up to 60 degrees latitude is being acquired.

K.S. Jayaraman 